\title{
POSSIBILITIES OF INDUSTRIAL UTILIZATION OF FFF/FDM PROCESS FOR CHOSEN ELEMENT PRINTING
}

\author{
Małgorzata Olender-Skóra, Wacław Banaś, Aleksander Gwiazda \\ Silesian University of Technology, Faculty of Mechanical Engineering, Department of \\ Engineering Processes Automation and Integrated Manufacturing Systems \\ Konarskiego 18A, 44-100 Gliwice, Poland \\ Corresponding author: Małgorzata Olender-Skóra, malgorzata.olender-skora@ polsl.pl
}

\begin{abstract}
D printing is a one of a new solution of manufacturing methods. This is caused by the ability of print a small part in a short time (rapid prototyping), but also because of the available materials. This is important because by using $3 \mathrm{D}$ printing, a specialized element is made for a specific apply. Compared with traditional production methods, such as turning and milling, 3D printing gives a wider possibility of making specific product patterns, thanks to which this method gained support and became a competitive one. Hence, the designing and manufacturing process based on it is more and more often referred as the "design-driven manufacturing". This method gives the possibility of making personalized elements or a larger number of product variants, but also gives the possibility of manufacturing complete elements in one run. The article describes the possibilities of using 3D printing in the production of unusual elements in a uncertain situations.
\end{abstract}

Key words: 3D printing, manufacturing, materials, customized products, $\mathrm{CAD}$.

\section{INTRODUCTION}

As the available technology is increasing, the opportunities of businesses also are growing. Manufacturers are looking for a new solution in manufacturing $[10,11,14,15]$. One of the areas, where advances are being seen is a $3 \mathrm{D}$ printing. This is caused by the ability of print a small part in a short time (rapid prototyping), but also because of the available materials. Another reason for the growing interest of this technology is also the increasingly popular production of customized products. 3D printing, as an innovation and alternative for traditional manufacturing, definitely fits into the trend. In addition to these elements, it is also important, that 3D printing is also one of the technologies of Industry 4.0. These technologies (Figure 1), combined with integration, are also a characteristic attribute of modern enterprises described as factories of the future $[1,8,21]$.
Regardless of the reasons for implementing 3D printing in businesses, this technology has much to offer to users. Also producers have a benefit from using these alternatives, which are still being developed.

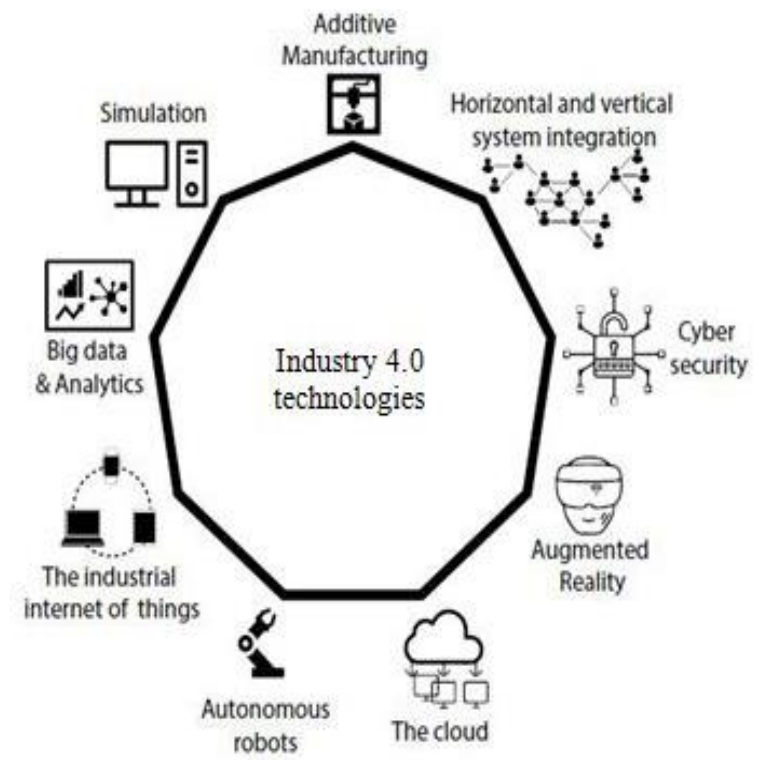

Fig. 1. Technologies of Industry 4.0 [16]

An additional advantage of using this solution is also the possibility of print a customized element, for which clients have to wait longer time of period or when the products generally is unavailable on the market. This is especially visible due to the existing pandemic, where some elements are unavailable. This also has impact to increase of interest of this technology. Of course, printed components can't be used everywhere, due to limitations for example materials, but it is a technology, that has a lot of potential. An additional benefit, for which manufacturers are increasingly like implement this solution, is a modified supply chain that saves time and costs.

This paper discusses about the 3D printing process 
and the four most commonly used printing methods. The realization of $3 \mathrm{D}$ printing process is also discussed on the example. This is an element, installed directly on the robot arm, on which the laser is mounted. This is important, because by using 3D printing, a specialized element is made for a specific apply. Through 3D printing, a customized element is made, which can solve a specific problem, connected with avability of elements on the market. Mentioned printout was made for the research in Department of Engineering Processes Automation and Integrated Manufacturing Systems, Faculty of Mechanical Engineering. In the article is also included a description of the process of creation the model in CAD program, until the finished print.

\section{3D PRINTING}

Interesting of 3D printing has grown significantly in recent years. Printing can now be seen in almost every field of industry. Printing capabilities have range from small parts to large components. The range of applications is large, because $3 \mathrm{D}$ printing is used in industry but also in medicine. It is an increasingly popular manufacturing alternative compared with traditional methods $[4,9,13]$.

\subsection{Methods of 3D printing}

The problem, which is important from the point of view of $3 \mathrm{D}$ printing is the available types of printers, because it determine the size of the print models and the type of printing technology. There are four main types of $3 \mathrm{D}$ printing $[3,5,9]$ :

- FFF/FDM method,

- SLA method,

- SLS method,

- CJP method

\section{FFF/FDM method}

This method is called Fused Filament Fabrication/Fused Deposition Modelling. It is a manufacturing of molten plastic. It consists of modeling a liquid thermoplastic material that is extruded in the form of a thin strand and placed on a work table. Filament dosing in a continuous way is possible by dosing the material in the form of a strand with a defined diameter. Filament with a given speed is transferred to the chamber of the melting system. These ensure a continuous inflow of molten material to the nozzle. In this method, the work table is lowered gradually successive, as layers of material are laid on, in accordance with created model. Creating model is a reproduction of the electronic model in .STL format. The precision of the printing, depends of the diameter of the nozzle, the precision of its positioning system, as well as the properties of the filament. In this method, printing is possible with one filament or two, using several heads. However, the disadvantage of this popular method is that, the printed layer must be positioned on a base because the melted filament must have support before hardens $[5,20]$.

\section{SLA method}

The method is called Stereolithography. It is a local polymerization of resins with UV laser light. It involves point curing of a liquid material, such as epoxy resin, with using a low-power laser beam. Exposed to ultraviolet light, the photo-cured resin is cured because of polymerization. Then, after the application and curing of one layer, this process is repeated for subsequent layers. The process ends, when the full model is made. In this method the device, includes a container with a light-curing liquid and, depending on the type of printer, successive layers cured on the surface of the liquid and also appropriate system raises and the level of the liquid with successive layers. Hardnes at the base of the photopolymer container is also possible. In this method, a light beam shines through the transparent bottom of the container and causes that the polymer harden on a platform, which slowly emerges from the container. In this method, it is important to add supports for elements that stand off from the surface of the object. The second important aspect is, ensure, that the current layer is equally covered with photopolymer before curing the next layer. Because of this, the printing time is increased. Another complication is that, the printed pieces are in one color - the printed object is immersed in a one-color liquid $[5,20]$.

\section{SLS method}

This method is called Selective Laser Sintering. This method involves selective laser melting of powders of different materials. In detail, layers of powder are applied to a work table and then are hardened by using a laser light sintering process. The laser causes that, the powder is heated locally, which ensures melts and fuses with the layers below. In this method, used materials are ceramic materials or metals as steel, bronze. The advantage of the method is that, there is no need to create supports for printed method. This is caused, that elements, which stand off from the surface of the object support themselves on the previous layers of building powder. But a disadvantage is the problem of powder getting into spaces of element, which are open $[4,5,20]$.

\section{CJP method}

This method is called Color Jet Printing. The principle of this method is similar as the SLS method. The building material in powder form is spread in 
subsequent layers on the print surface. This process begins with the application of a layer of gypsum powder, which is spread over the surface of the printer's work table. Then, a print head moves over the powder layer, which selectively sprays the binder and color. Binder causes that, the powder binds to itself and colours for the requested color. When the process of applying the first layer is complete, the next layer of powder is applied. The unglued powder, is used as a support for the parts of the model. When the model is finished, is removed from the powder and then cleaned. Then, after cleaning, the models are immersed in a special chemical liquids. This improves mechanical strength and colors of the element. The advantage of this method is the possibility to re-use powder, that has not been glued with a binder (don't lose physical properties). However, a disadvantage of this method is the existence of surface roughness - the uneven spreading of the binder over the build material. A second disadvantage is that the models are in the form of gypsum printouts and cannot be used in mechanical applications [5, 18, 20, 22].

\subsection{Advantages and disadvantages of 3D printing}

In addition to manufacturing methods, which have limitations, the material, from which the printouts are made, is also important due to the possibility of its application fields. In general, the most commonly used materials are: metal, super-alloys, polymers, composites and ceramics, plastics, glass, wax, glue mixes, nylon. Also, researches are conducted to expand the range of materials used in 3D printing and application of different types of mixtures, i.e. mixture with wood $[2,7,12,17]$.

3D printing becomes more popular. The development of this type of manufacturing is connected by its advantages $[1,13]$ :

- make a quick prototype;

- access to various materials;

- analysing the prototype;

- access to different types of printers;

- access to libraries from any computer;

- shorter delivery time.

However, like any manufacturing method, this method has also disadvantages, such as $[1,13]$ :

- long printing time of complex elements;

- possible defects in the printed elements;

- high cost of printers;

- unclear intellectual property;

- liability problems - warranties, certification.

Despite the disadvantages of 3D printing, this technology has potential. This is especially visible today with customized production and when the component is not available on the market. The ability to print a component, that is needed at a certain point of time, offers great opportunities for flexible production and a further development of this technology. Popularization of 3D printing and lowering costs of this process, creates the possibility of producing not only prototypes, but also short production series (rapid manufacturing). Realizing printing tasks, the first step is attention to the application of the printed element and to the appropriate choice of material.

In the next part of the article the steps of making the model and the completed printout realized for the purpose of research are showed. This is important because by using addfitive manufacturing, specialized elements are made for a specific application. Through 3D printing, customized elements are made, which solve a problem with available of specific elements on the market.

\section{CREATING OF PRINTING MODEL}

3D printing is a technology that allows made products according to customer specifications. It is more useful, if the necessary components and their parts are not available on the market. For the purpose of this research, a printout of the element that is directly mounted to the robot arm was created. Additionally in next step a laser was mounted to the printout. So in the first step, a model of the element was created in a CAD program (Figure 2).

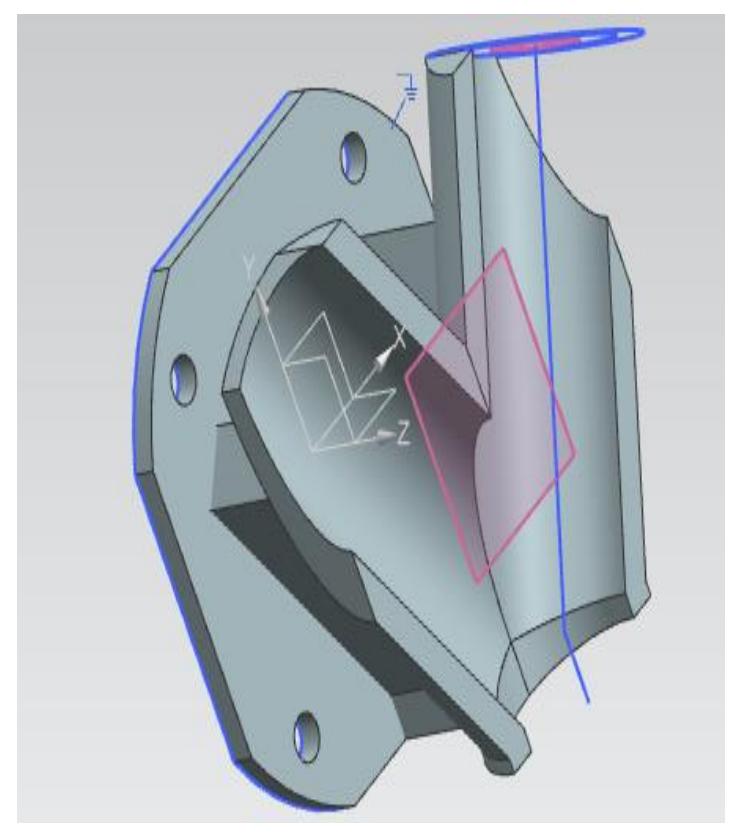

Fig. 2. Part of model in CAD program

This model was designed, according to the hole spacing and screw diameters for the gripper from the kit of robot. The completed model made in CAD program is showed in Figure 3. 


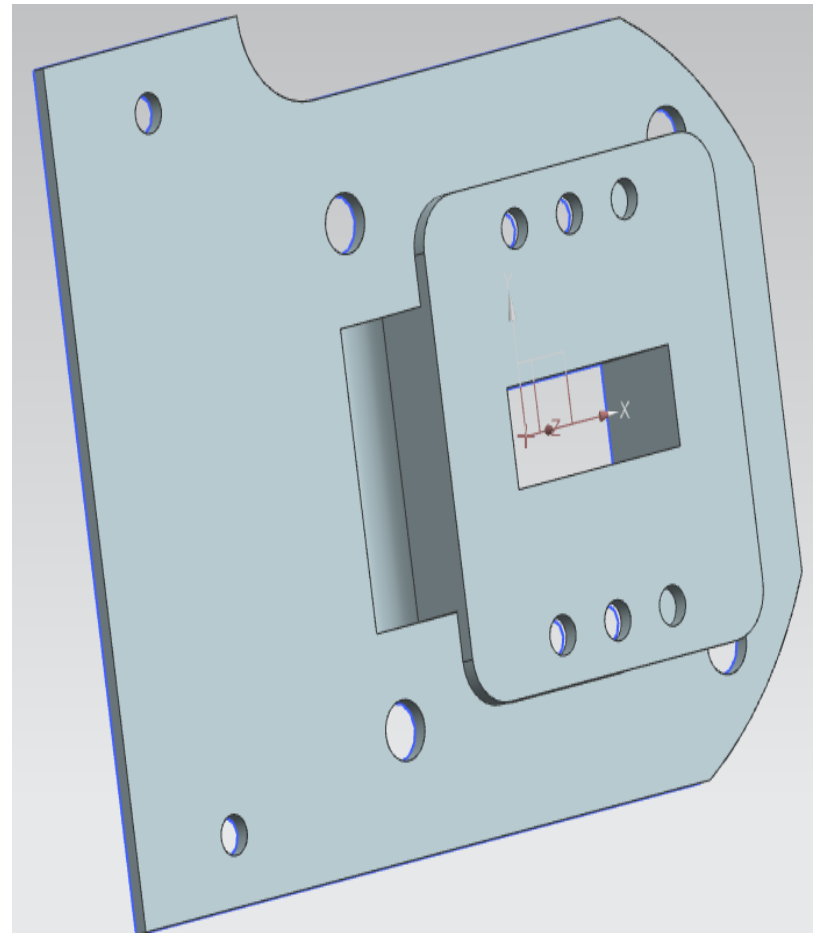

Fig. 3. Model in CAD program

After creating model in $\mathrm{CAD}$ program, the next step is the export file to.STL version (Figure 4).

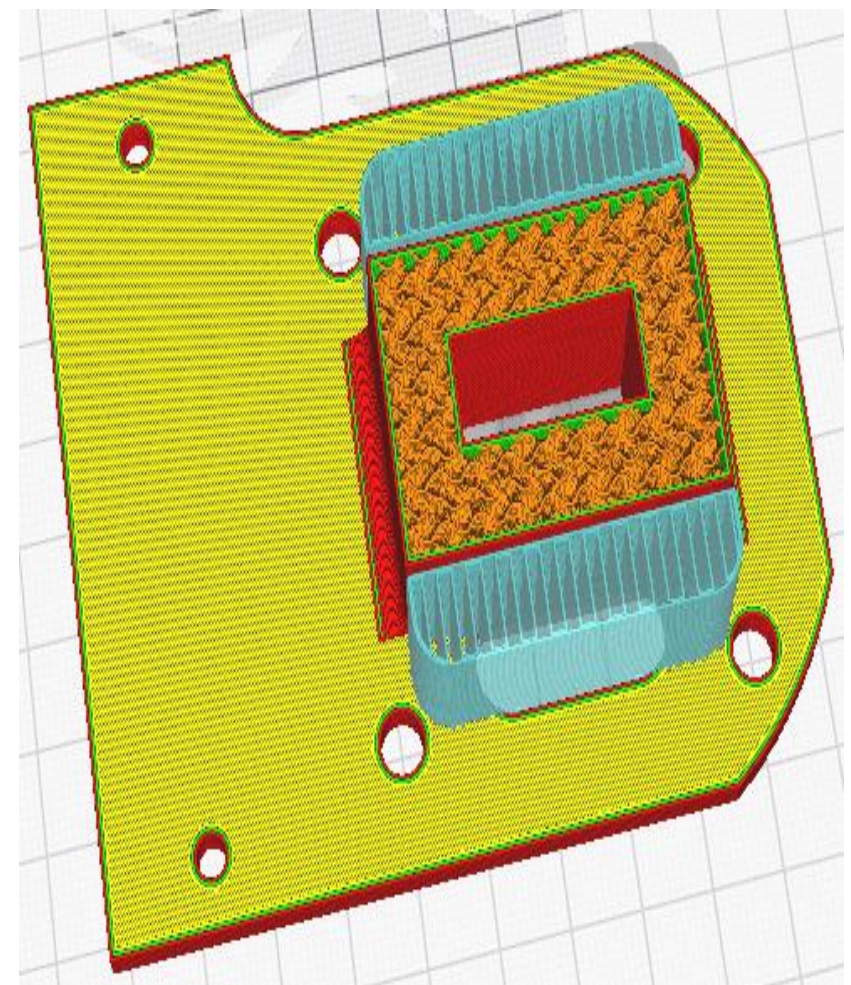

Fig. 4. Model in .STL version

A print in .STL version is also for checking and verifing the design model. This is for interpretation, whether the surface is damaged or whether there are other errors. If everything is correct, in the next step the printing process is started.

In this example, the model was printed from a PP (polipropylen) material. It is a material used in industry, such as automotive or in medicine. This material is characterized by high flexibility, resilience and durability [19].

The complete printing of the model took $6 \mathrm{~h}$ and 9 minutes and was made on Prusa i3 printer (Figure 5).

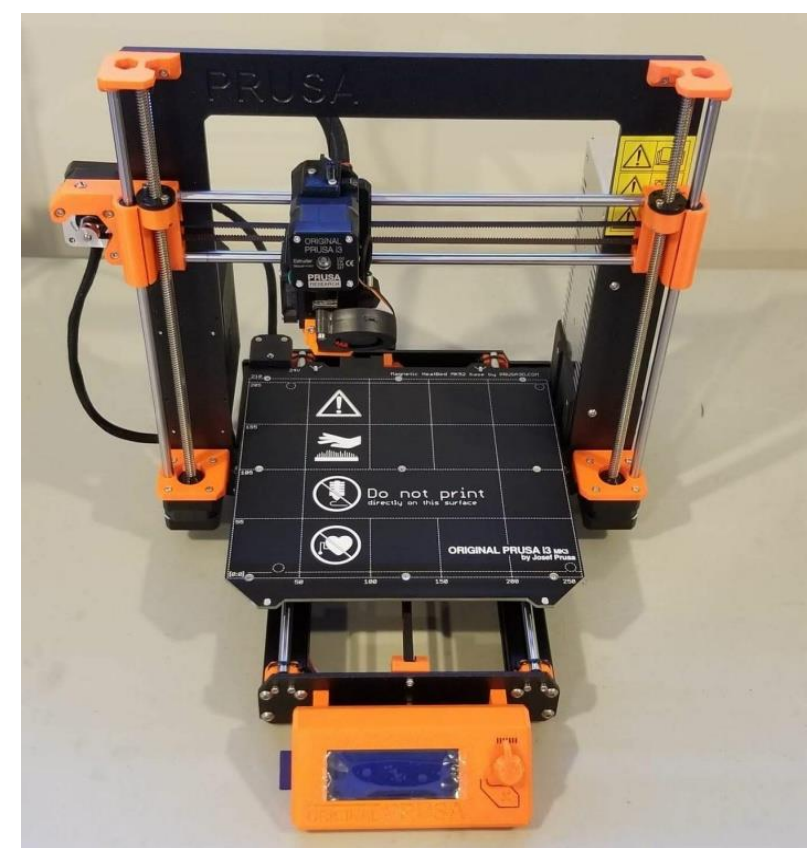

Fig. 5. Prusa i3 printer [22]

The printed model weight is $48 \mathrm{~g}$ and $16 \mathrm{~m}$ of material was used to print this element. The diameter of the filament was $1.75 \mathrm{~mm}$. Printed element is showed in Figure 6(a) and 6(b).

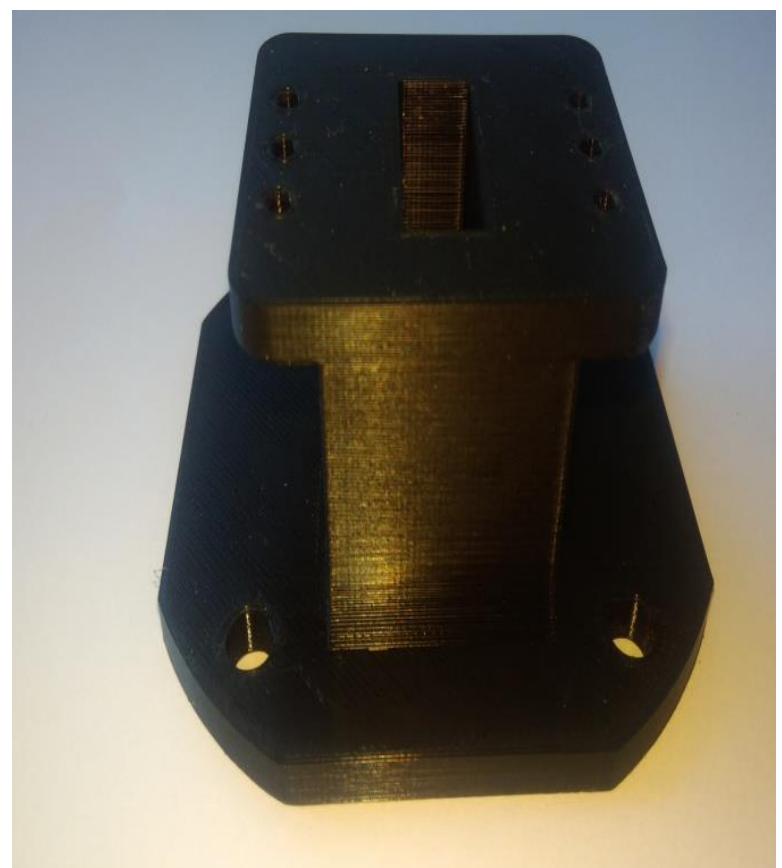

(a) 


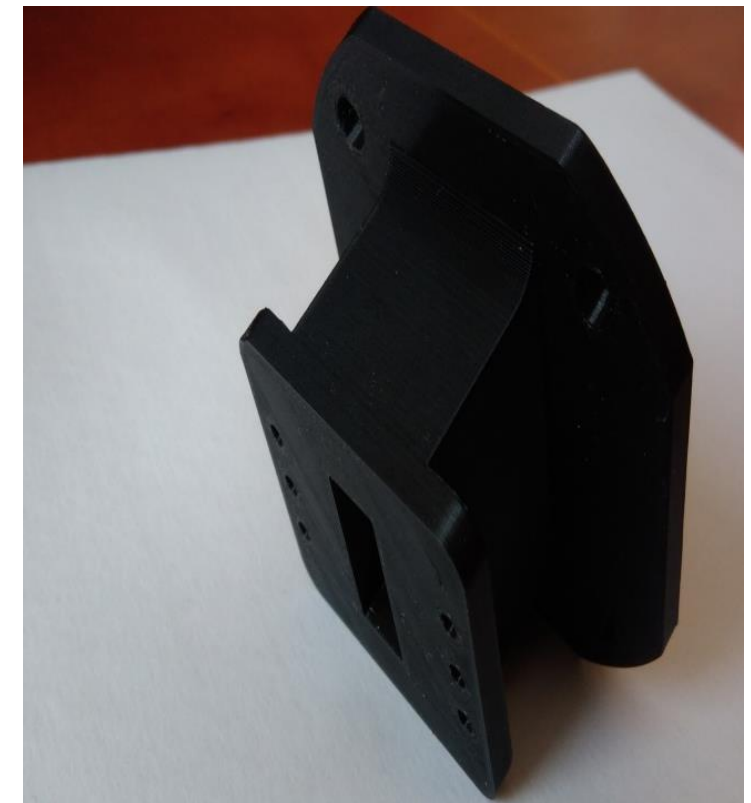

(b)

Fig. 6. Completed model printout

The printed element was used as an element mounted to the robot arm, to which the laser is fitted. The printout fulfilled the requirements both in terms of quality and will be used in further research. The use of 3D printing has many advantages, especially considering that, the printing is also in according to the idea of "design-driven manufacturing". All, what is required is: the appropriate CAD software, a printers, filaments, and the concept of element, which can be printed. In this way, the required component, according to requirements is achieved, without waiting for external delivery of this component. This is also according to the increasingly visible trend, socalled customized production.

\section{FURTHER WORKS}

The discussed process of printing an element by using $3 \mathrm{D}$ printing is the beginning of the realization of further research. This research will be related with the printing process, the possibilities of this method, the study of materials used for a specific solution, but also will be related with the possibility of creating a printout, according to the idea: need-designimplementation. Moreover, this research will be related also with verification, if the modifications introduced to the printouts will work in different conditions, or used filaments are appropriate. Another part of research, related with 3D printing will be solutions connected with other technologies from Industry 4.0, including integration and automation of realized processes. The last part of the research will involve also issues related to the influence of $3 \mathrm{D}$ printing on the supply chain and its modification to the traditional model as a result of changes occurring in the market and in the area of manufacturing.

\section{CONCLUSIONS}

Nowadays, the shortest time and flexibility in manufacturing are more important. Also the issue of castomization of products is becoming more popular. Therefore manufacturers are looking for new solutions, also in the field of manufacturing. From recent year an interest of 3D printing significantly is growing. This is caused of access to printers, but also to better filaments. Currently this method of manufacturing is used in industry, but also in civil engineering or medicine. Now it is possible to print more complex elements, which can be quickly adapted to individual needs.

In article, the $3 \mathrm{D}$ printing method and the main methods are described. The examples of materials, which can be used for 3D printing are also indicated. In the next part of the article, the steps related with modeling an specialised element in CAD program and then transferring to .STL version are described. The example of solution was an element that was mounted on the robot arm, according to the distance between the holes and the diameters of the screws for the gripper from the kit robot. This element was printed from PP (polypropylene) material. Printing of the model took $6 \mathrm{~h}$ and 9 minutes. The model has $48 \mathrm{~g}$ weight, and for the print used $16 \mathrm{~m}$ of material. This printout was made for purpose of research in Department of Engineering Processes Automation and Integrated Manufacturing Systems, Faculty of Mechanical Engineering. The printout fulfilled the requirements in terms of quality as well as the possibility of using this element for further research. The problem discused in article is important because by using 3D printing, a specialized element is made, which can be using in specific apply.

Further research will include modifications to the printouts and also on verifying them under different conditions, connected with used of various filaments. Also future works will concern on solutions related with Industry 4.0 technologies, including integration and automation of realized processes.

\section{REFERENCES}

1.Alfaify, A., Saleh, M., Abdullah, F.M., et. all, (2020). Design for additive manufacturing: a systematic review, Sustainability 12(19), 1-22

2.Alghamdy, M., Ahmad, R., Alsayyed, B., (2019). Material selection methodology for additive manufacturing applications, Procedia CIRP 84, 486490

3.Borysiewicz, A., Gonera, P., Lęgowik, D., Dembiczak, T., Gospodarek, K., (2018). Use of incremental method in prototyping (in Polish), Prace Naukowe Akademii im. Jana Długosza w Częstochowie. Technika, Informatyka, Inżynieria 
Bezpieczeństwa 6, 45-56

4.Caban, J., Szala, M., Kęsik, J., Czuba, Ł., (2017).

Use of $3 D$ printing in automotive industry (in Polish), Autobusy 6, 573-579

5.Cichoń, K., Brykalski, A., (2017). Industrial use of $3 D$ printers (in Polish), Przegląd Elektrotechniczny 3, 156-158

6.De Jong, J.P.J., de Bruijn, E., (2013). Innovation lessons from 3-D printing, Mit Sloan Management Review 54(2), 42-53

7.Grabowik, C., Kalinowski, K., Ćwikła, G., Krenczyk, D., (2015). A review of rapid manufactured parts post processing methods, Selected Engineering Problems 6, 27-32.

8.Kampa, A., Olender, M., (2020). $3 d$ printing as new technology in perspective of industry 4.0, International Journal of Modern Manufacturing Technologies XII(2), 70-79

9.Kordowska, M., Choromańska, M., Musiał, W., Plichta, J., (2015). 3D printing in the automotive industry (in Polish), Autobusy 6,123-128

10. Lysek, K, Gwiazda, A, Herbuś, K., (2019). The use of the NX mechatronic module to simulate of a simple machine work. IOP Conf Ser: Mater Sci Eng 591, 1-7

11.Nalepa, B., Gwiazda. A., Banaś, W., (2018). Investigation of movement of mobile robot work, IOP Conf Ser: Mater Sci Eng 400, 1-9

12.Ngo, T. D., et al., (2018). Additive manufacturing (3D printing): A review of materials, methods, applications and challenges, Composites Part B: Engineering 143, 172-196

13.Olender M., (2020). Work stands modeling in additive manufacturing, International Journal of Modern Manufacturing Technologies 12(3), 98-105

14. Olender, M., (2020). Business process modeling for flexible tasks workflow, IOP Conf Ser: Mater Sci Eng 916, 1-7

15.Paprocka, I., Krenczyk, D., Burduk. A. (2021). The method of production scheduling with uncertainties using the ants colony optimisation, Appl. Sci 11(1):171, 1-14

16. Saucedo, J., Lara, M., Marmolejo, J., Salais, T., et. all., (2018). Industry 4.0 framework for management and operations: a review, Journal of Ambient Intelligence and Humanized Computing 9(3)

17.Singh, S., Ramakrishna, S., Singh, R., (2017). Material issues in additive manufacturing: A review, Journal of Manufacturing Processes 25, 185-200

18. Ślusarczyk, P., (2017). Introduction to CJP technology (in Polish), Available from: https://centrumdruku3d.pl/wprowadzenie-

technologii-cjp/, Accesed: 07.04.2021

19. Ślusarczyk, P., (2020). $3 D$ printing from PP (polypropylene) (in Polish), Available from: https://centrumdruku3d.pl/druk-3d-z-pp-

polipropylenu/, Accesed: 07.04.2021

20.Tatarczak, J., Krzysiak, Z., Samociuk, W., Kaliniewicz, Z., Krzywonos, L., (2017). Overview of modern $3 D$ printing technologies for metal objects (in Polish), Mechanik 7, 612-614

21.Thompson, M.K., Moroni, G. Vaneker, et. all. (2016). Design for Additive Manufacturing: Trends, opportunities, considerations, and constraints, CIRP Annals 65(2), 737-760

22. Available from:

https://www.ordsolutions.com/original-prusa-i3-mk3assembled-3d-printer/, Accesed: 10.04.2021

Received: April 19, 2021 / Accepted: December 20, 2021 / Paper available online: December 25, 2021 (C) International Journal of Modern Manufacturing Technologies 